explored with support from Macmillan. Quarterly meetings have been planned for the next year with the aim of keeping the momentum going in each of the nurses clinical environments. A web based resource is being developed that will support nurses to foster a culture of enquiry, develop their own research practices and enable others to engage in research activity.

Application to hospice practice Two nurses work specifically in hospices and are currently developing ward based projects to enhance the frontline staffs ability to participate in research. Others work in CNS roles and on wards in the acute sector and are looking at how they can further develop and encourage colleagues to become involved in the research process in some way.

\section{P60 THE EXPERIENCE OF RECRUITING HOSPICE PATIENTS, FAMILY MEMBERS AND HEALTH CARE PROFESSIONALS TO A QUALITATIVE RESEARCH STUDY}

${ }^{1}$ Rachel Perry, ${ }^{2}$ Rosanna Orlando, ${ }^{2}$ Joanna Coast, ${ }^{1}$ Kathy Armour. ${ }^{1}$ Marie Curie Hospice, West Midlands, Solihull, UK, ${ }^{2}$ Health Economics Unit, University of Birmingham

\subsection{6/bmjspcare-2013-000591.82}

Background A single patient recruitment site hospice and local university partnership has been established for a European Research Council funded research study. It aims to assess the validity of a supportive care measure in patients receiving end of life care, people close to them (CPs) and primary healthcare professionals (HCPs). The recruitment targets are 35 patients, 20 CPs and 20 HCPs. A hospice nurse $(\mathrm{HN})$ identifies participants prior to recruitment by university researchers.

Aim To establish successful patient recruitment in a hospice new to research.

Approach Used The HN liaised with the multidisciplinary team (MDT) to identify eligible patients and provide support; she also approached all eligible patients in her own area of practice, day services. Facilities (e.g. interview rooms) were organised for researchers to recruit and interview participants.

Outcomes To date, 22 patients have been introduced to the study by the $\mathrm{HN}$ and given a patient information leaflet. 6 patient follow-ups are pending and 3 interviews have been booked. 5 patients have been recruited from Day Hospice. With permission from patients, $2 \mathrm{CPs}$ and 4 HCPs have been interviewed.

Challenges affecting recruitment include environmental issues (moving hospice); ethical issues (amendment required); poor health status of patients and their cyclical involvement in daycare.

Remedies include (i) dialogue with patients and staff reducing concerns about the research nurse's potential conflict in duties; (ii) communication reducing the reluctance of staff to "over-protect" patients and allow recruitment; (iii) extension of participants to community and IPU patients improving recruitment rates; (iv) adaptation of patient management system to administer interactions for research.

Application to Hospice Practice Our study explored methods of recruitment of patients to research. Improvements include communication of goals with hospice colleagues and university researchers and a growing confidence in approaching patients. Recruitment experience will change practice in this and future studies.

\section{Leadership, organisation and management}

\section{P61 HOW DO HOSPICES PERCEIVE THEIR ROLE IN THE CURRENT HEALTH CARE ENVIRONMENT? A VIEW FROM THE TOP}

Gaberielle Linehan. St Raphael's Hospice, North Cheam, England

\subsection{6/bmjspcare-2013-000591.83}

A qualitative study using a critical review of the literature and semi structured interviews with a small sample of Hospice Chief Executives explored their perceptions of the impact and effect of the national policy agenda on their organisation and hospice care in England.

The findings from the research indicate that hospice services continue to be influenced by their history and legacy. The 'arrogance' of hospice organisations viewing themselves as 'set apart' and in charge of their own destiny is set to be challenged by the new world of commissioning. Operating outside the National Health Service but dependent on partial funding to provide end of life care services to patients, they are trying to be innovative, challenge existing cultural norms, engage a wider populace and redefine the parameters of what they can offer while maintaining 'independence'.

The national drive to support care in the community is refocusing hospice care into the community with outreach support and engagement with other provider services, rather than inpatient provision. This integrated approach poses conceptual difficulty for hospice staff.

The balancing of the historic context with external demands of an ever changing health care landscape focused the CEOs interviewed to discuss the change in identity of hospice from a 'building', to a community outreach service with access to specialist resources- a significant turning point. Increased visibility impacted on how hospice was viewed by the wider healthcare economy, rather than, 'do gooding' little charities, but as part of whole service provision. The struggle between independence and integration is a tension for hospice particularly related to outcomes and demonstrating the unique role of palliative and EoLC.

The study also highlighted how policy has influenced hospice to reframe as small business units taking a commercial view of their service configuration which all CEOs viewed as a challenge.

\section{P62 MANAGING CHANGE IN CHALLENGING TIMES}

Nicola Parkes. Trinity Hospice, Blackpool, England

\subsection{6/bmjspcare-2013-000591.84}

Introduction As hospices face challenges, there is a need to balance the economic cost and the demands placed upon the services we provide, leading to new ways of working and changes within the organisation.

Change can be difficult and can often be seen as being "done to" as opposed to being "part of "the process.

Aims The aim was to find a simple tool to use within teams to engage them in the change process and to illicit issues that where pertinent to them in the future development of the service, and to identify areas in which efficiencies could be made. 
Method We devised a simple tool which enabled staff to state what they wanted to "Stop, Start and Keep" within the services they provided.

Discussion This tool was used in an "away day" style environment, the whole team where engaged in the process and the use of the tool elicited themes from the team in relation to the questions asked, and enabled the team to develop a plan for future developments and discuss key areas of concern.

There was an over arching theme related to maintaining quality which underpinned all such developments and a desire to ensure the quality of care patients received was not adversely affected. The use of the tool acted as a bench mark to where we are now and where we wanted to be, and enables the team to review progress, its impact and celebrate success.

Conclusion The use of this tool enabled the team to feel engaged and contribute to the development of new ideas and ways of working in challenging times. The process is fluid and enables teams the opportunity to revisit and review and address issues and developments.

\section{P63 FIT FOR THE FUTURE.... EMPOWERING AN ORGANISATION THROUGH STRATEGY DELIVERY}

Roslyn Neely. Children's Hospice Association Scotland, Edinburgh, UK

\subsection{6/bmjspcare-2013-000591.85}

Background The organisation has created a visionary strategy to position them as an influential, leading paediatric palliative care provider in Scotland, the UK and beyond. In creating this, there was an opportunity to truly engage with all those involved in the organisation; reflecting visions and hopes for the future through collaboration and consultation. Children, young people and families using the services; trustees, staff and volunteers were consulted through a series of focus groups, externally facilitated to maximise objectivity. This was the starting point for a dynamic ongoing strategic planning process to ensure the organisation is in a strong position to meet the changing needs of babies, children, young people and their families in a changing political and financial landscape.

Method A number of sessions were held to explore what the future might hold for the organisation over the next ten years. This has included exploring the changing needs of the children, young people and families who will use the service; considering new ways of delivering care, skill mix review, the hospice environment, income and expenditure projections, the political landscape, policy and partnership working with statutory and voluntary organisations.

Outcomes Two years on and the resulting strategic plan is delivering measurable outcomes which are positively impacting on the care and support being given to families. The organisation has also influenced the development of a Framework for the Delivery of Palliative Care for Children and Young People (2013). Staff, volunteers and service-users are motivated, guided and empowered by the plan. The plan has raised awareness of the organisation within health and local authority networks, resulting in increased referrals and funding.

\section{P64 FINANCIAL PLANNING FOR UNCERTAINTY}

Alison Ryan, Sheena Keep. Weldmar Hospicecare Trust, Dorchester, United Kingdom

10.1136/bmjspcare-2013-000591.86
Introduction In common with other independent hospices, Weldmar Hospicecare Trust faces considerable uncertainty over the size and nature of future income. This paper describes the financial modelling which allows us to make sound financial plans despite that uncertainty.

Aims To create an understanding of our complex finances so we can focus on the most impactful income generation, control expenditure and use our Balance Sheet strength to create a future where we are no longer dependent on any one source of income.

Approach used

- analysis of expenditure and income steams by type and cost centre (80 + budget lines).

- Application of differential growth/cost pressure assumptions to each line on an Excel model which allows assumptions to be changed producing different results.

Outcomes this command of our finances has allowed us to:

- make budget adjustments in the context of securing long term strength,

- to manage sudden unforeseen changes (such as $90 \%$ failure of legacy income in one year) without making damaging short term cuts,

- to distribute resources to staff via pay in a way which is sustainable and transparent and affordable,

- to invest in income raising possibilities even while running planned $£ 1$ million deficits.

Our model shows that in four years' time we will have generated sufficient surplus to minimise the impact of loss or reduction of NHS income should competitive tendering produce such a result. It provides a clear guide to managers on how service development can, or cannot, be afforded.

Application to hospice practice Hospices have complex and unpredictable income streams - NHS, trading, legacies, donations, investment and relatively fixed costs - largely staffing. Without a long term view, short term reactions to financial hiatus can lead to unnecessary curtailment of services, loss of opportunity and lowered morale. This model minimises those problems.

\section{P65 DEVELOPING A CULTURE OF GOOD LEADERSHIP AND MANAGEMENT}

Lynn Kelly, Stephen Greenhalgh. St Catherine's Hospice, Preston, United Kingdom

10.1136/bmjspcare-2013-000591.87

\section{Background}

- Little interaction between managers across different directorates

- No sense of 'team' amongst managers

- Lack of consistent approach and varying degrees of management experience

Aim

- Set standard for leadership \& management amongst middle managers

- Raise confidence of managers in dealing with staff performance

- Develop team working across departments

- Enable managers to contribute to and deliver the Hospice 5 year plan

Approach Used 